\title{
PENERAPAN METODE EXTREME PROGRAMMING DALAM PERANCANGAN APLIKASI PERHITUNGAN KUOTA SKS MENGAJAR DOSEN
}

\author{
Irmawati Carolina $^{1}$, Adi Supriyatna ${ }^{2}$ \\ ${ }^{1}$ Universitas Bina Sarana Informatika Jakarta \\ J1. Kamal Raya No.18 Ringroad Barat Cengkareng Jakarta Barat \\ E-mail : irmawati.imc@bsi.ac.id \\ ${ }^{2}$ Universitas Bina Sarana Informatika Jakarta \\ J1. Kamal Raya No.18 Ringroad Barat Cengkareng Jakarta Barat \\ E-mail : adi.asp@bsi.ac.id
}

\begin{abstract}
ABSTRAK
Perhitungan kuota sks mengajar dosen menjadi kegiatan yang rutin dilakukan setiap bulan yang dijadikan sebagai acuan untuk pembayaran honor mengajar dosen serta pengambilan keputusan manajemen. Perhitungan sks mengajar yang dilakukan secara manual membutuhkan waktu yang cukup lama dikarenakan jumlah dosen yang semakin banyak. Selain itu sering terjadi kesalahan dan kekeliruan dalam proses perhitungan sks dan menimbulkan keluhan dari dosen yang mengajar pada setiap semester.Tujuan penelitian ini membangun sebuah aplikasi yang dapat melakukan perhitungan jumlah sks mengajar dosen dengan cepat dan tepat. Merancang suatu aplikasi tentunya membutuhkan suatu metode yang khusus untuk membantu selama proses pengerjaan. Berdasarkan kebutuhan perkembangan metode menjadi salah satu unsur yang penting dalam perkembangan kebutuhan informasi. Metode yang digunakan pada perancangan aplikasi ini adalah Extreme Programming yang merupakan metode yang memiliki empat tahapan dalam pelaksanaannya, yaitu perencanaan, perancangan, pengkodean dan pengujian. Dengan melaui keempat tahap tersebut diharapkan hasil yang diperoleh menjadi maksimal dan dapat lebih membantu dalam prose yang dibutuhkan. Hasil dari penelitian ini berupa aplikasi pemetaan kuota sks mengajar dosen yang dapat memberikan kemudahan dan keakuratan dalam perhitungan jumlah sks mengajar dosen dengan cepat dan tepat, mampu mengurangi kesalahan dalam proses perhitungan dan dapat meminimalisir komplain dari dosen terkait honor mengajar yang diperoleh.
\end{abstract}

Kata kunci : Extreme Programming, Pemetaan SKS.

\section{ABSTRACT}

Quota calculation for teaching lecturers to become routine activities carried out every month which is used as a reference for payment of honorarium teaching lecturers and management decision making. Calculation of teaching credits that are done manually requires quite a long time due to the increasing number of lecturers. In addition, mistakes and errors often occur in the credit calculation process and cause complaints from lecturers who teach in each semester. The purpose of this study is to build an application that can calculate the number of credits to teach lecturers quickly and accurately. Designing an application certainly requires a method that is specific to help during the process. Based on the developmental needs of the method, one of the important elements in the development of information needs. The method used in the design of this application is Extreme Programming which is a method that has four stages in its implementation, namely planning, designing, coding and testing. Through these four stages, it is expected that the results will be maximized and can be more helpful in the process needed. The results of this study in the form of a quota mapping application teaching lecturers that can provide convenience and accuracy in calculating the number of credits teaching lecturers quickly and accurately, able to reduce errors in the calculation process and can minimize complaints from lecturers related to teaching fees obtained.

Keywords: Extreme Programming, SKS Mapping. 


\section{PENDAHULUAN}

Dosen adalah salah satu komponen yang terpenting dalam sistem pendidikan di perguruan tingg. Dalam undang-undang nomor 14 tahun 2005 tentang guru dan dosen, dinyatakan bahwa dosen sebagai pendidik profesional dan ilmuwan dengan tugas utama mentransformasikan, mengembangkan dan menyebarluarkan ilmu pengetahuan, teknologi dan seni melalui tri dharma perguruan tinggi. Perhitungan kuota sks mengajar dosen menjadi kegiatan yang rutin dilakukan setiap bulan yang dijadikan sebagai acuan untuk pembayaran honor mengajar dosen serta pengambilan keputusan manajemen. Perhitungan sks mengajar yang dilakukan secara manual membutuhkan waktu yang cukup lama dikarenakan jumlah dosen yang semakin banyak. Selain itu sering terjadi kesalahan dan kekeliruan dalam proses perhitungan sks dan menimbulkan keluhan dari dosen yang mengajar pada setiap semester.

Menurut (Pardede \& Novriyenni, 2018) penentuan jumlah sks yang diberikan kepada dosen merupakan masalah yang harus ditangani secara baik dan cepat, dikarenakan masalah ini akan selalu timbul setiap semester. Penentuan jumlah sks yang diberikan kepada dosen harus sesuai dengan kemampuan, kesanggupan dan profesional dosen yang bersangkutan.

Tujuan penelitian ini membangun sebuah aplikasi yang dapat melakukan perhitungan jumlah sks mengajar dosen dengan cepat dan tepat. Merancang suatu aplikasi tentunya membutuhkan suatu metode yang khusus untuk membantu selama proses pengerjaan. Berdasarkan kebutuhan perkembangan metode menjadi salah satu unsur yang penting dalam perkembangan kebutuhan informasi.

\section{METODOLOGI}

Dalam pembangunan sistem informasi atau aplikasi terdapat beberapa pendekatan atau metodologi yang dapat digunakan antara lain System Development Life Cycle (SDLC), Rapid Application Development (RAD), Extreme Programming (XP) dan lain sebagainya. Pada penelitian ini metologi yang digunakan dalam pembangunan aplikasi perhitungan sks mengajar kuota sks mengajar dosen adalah metode Extreme Programming $(X P)$. Menurut Prabowo dalam (Supriyatna, 2018) Extreme Programming (XP) merupakan sebuah proses rekayasa perangkat lunak yang cenderung menggunakan pendekatan berorientasi objek dan sasaran dari metode ini adalah tim yang dibentuk dalam skala kecil sampai medium serta metode ini juga sesuai jika tim dihadapkan dengan requirement yang tidak jelas maupun terjadi perubahan-perubahan requirement yang sangat cepat.

Sedangkan menurut Ferdiana dalam (Lubis, 2016) Extreme Programming (XP) dikenal dengan metode atau "technical how to" bagaimana suatu tim teknis mengembangkan perangkat lunak secara efisien melalui berbagai prinsip dan teknik praktis pengembangan perangkat lunak. XP menjadi dasar bagaimana tim bekerja seharihari.

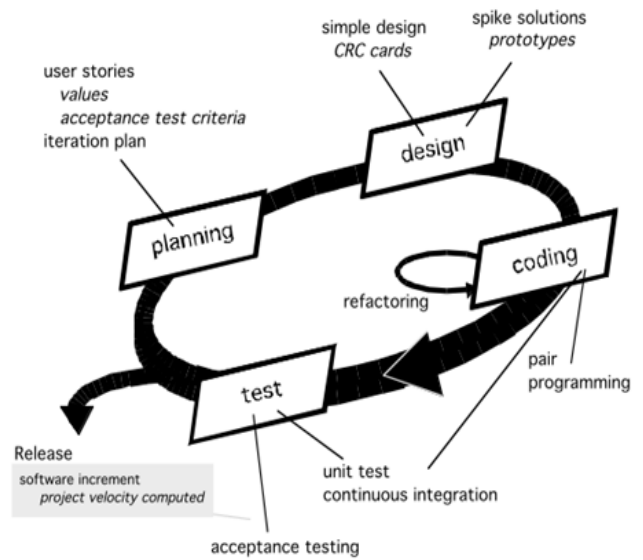

Gambar 1. Metode Extreme Programming.

Terdapat empat tahapan yang harus dikerjakan pada metode extreme $\operatorname{programmin}(x p)$ yaitu:

1) Planning (Perencanaan).

Tahapan ini merupakan langkah awal dalam pembangunan sistem dimana dalam tahapan ini dilakukan beberapa kegiatan perencanaan yaitu, identifikasi permasalahan, menganalisa kebutuhan sampai dengan penetapan jadwal pelaksanaan pembangunan sistem.

2) Design (Perancangan).

Tahapan berikutnya adalah perancangan dimana pada tahapan ini dilakukan kegiatan pemodelan yang dimulai dari pemodelan sistem, pemodelan arsitektur sampai dengan pemodelan basis data. Pemodelan sistem dan arsitektur 
menggunakan diagram Unified Modelling Language (UML) sedangkan pemodelan basis data menggunakan Entity Relationship Diagram (ERD).

3) Coding (Pengkodean).

Tahapan ini merupakan kegiatan penerapan pemodelan yang sudah dibuat kedalam bentuk user inteface dengan menggunakan bahasa pemrograman. Adapun bahasa pemrograman yang digunakan adalah PHP dengan metode terstruktur. Untuk sistem manajemen basis data menggunakan piranti lunak MySQL.

4) Testing (Pengujian).

Setelah tahapan pengkodean selesai, kemudian dilakukan tahapan pengujian sistem untuk mengetahui kesalahan apa saja yang timbul saat aplikasi sedang berjalan serta mengetahui apakah sistem yang dibangun sudah sesuai dengan kebutuhan pengguna. Metode pengujian yang digunakan pada tahapan ini adalah metode blackbox testing, dimana pengujian yang dilakukan terhadap form beberapa masukkan apakah sudah berjalan sesuai dengan fungsinya masingmasing.

\section{LANDASAN TEORI}

\section{Sistem Informasi}

Menurut (Romney \& Steinbart, 2015) Sistem adalah rangkaian dari dua atau lebih komponen-komponen yang saling berhubungan, yang berinteraksi untuk mencapai suatu tujuan.Sebagian besar sistem terdiridari subsistem yang lebih kecil yang mendukung sistem yang lebih besar. Sedangkan pengertian sistem informasi menurut (Krismiaji, 2015) adalah cara-cara yang diorganisasi untuk mengumpulkan, memasukkan, dan mengolah serta menyimpan data, dan cara-cara yang diorganisasi untuk menyimpan, mengelola, mengendalikan, dan melaporkan informasi sedemikian rupa sehingga sebuah organisasi dapat mencapai tujuan yang telah ditetapkan

\section{Visual Basic 6.0.}

Visual Basic merupakan sebuah bahasa pemrograman yang menawarkan Intergrated Development Environment (IDE) visual untuk membuat program perangkat lunak berbasis operasi Microsoft Windows menggunakan model pemrograman (COM) (Stefano, 2014). Menurut Sunyoto dalam (Wina Widiati, 2017) Visual Basic adalah program untuk membuat aplikasi berbasis Microsoft Windows secara cepat dan mudah. Visual Basic menyediakan tool untuk membuat aplikasi yang sederhana sampai aplikasi kompleks atau rumit baik untuk keperluan pribadi maupun untuk keperluan perusahaan/instansi dengan sistem yang lebih besar.

\section{Unified Modelling Language(UML)}

UML (Unified Modeling Language) adalah bahasa pemodelan untuk sistem atau perangkat lunak yang berparadigma berorientasi objek. Pemodelan (modeling) sesungguhnya digunakan untuk penyederhanaan permasalahan-permasalahan yang kompleks sedemikian rupa sehingga lebih mudah dipelajari dan dipahami (Nugroho, 2010). Menurut (Sukamto \& Shalahuddin, 2014) UML terdiri dari 13 macam diagram yang dikelompokkan dalam 3 kategori. Pembagian kategori dan macammacam diagram tersebut dapat dilihat pada gambar dibawah ini:

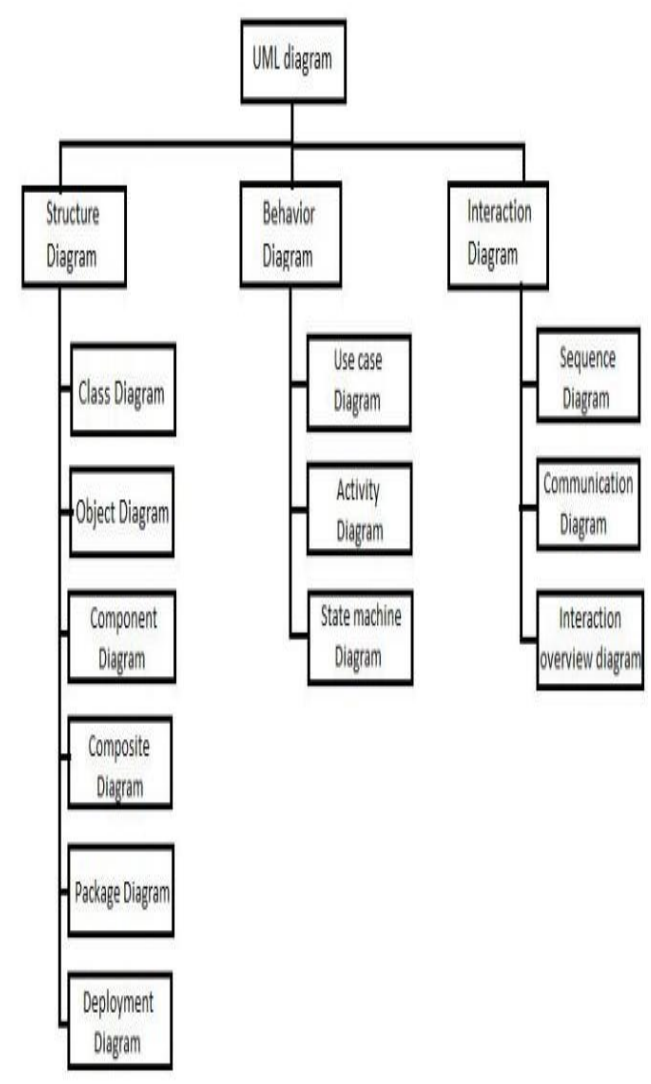

Gambar 2. Diagram UML. 


\section{Entity Relationship Diagram (ERD)}

ERD dikembangkan berdasarkan teori himpunan dalam bidang matematika. ERD digunakan untuk pemodelan basis data relasional. Sehingga jika penyimpanan basis data menggunakan OODBMS maka perancangan data tidak perlu menggunakan ERD (Lubis, 2016).

\section{Basis Data}

Menurut Fathansyah dalam (Wina Widiati, 2017) menjelaskan bahwa Basis data terdiri atas 2 kata, yaitu Basis dan Data. Basis kurang lebih dapat diartikan sebagai markas atau gudang, tempat bersarang atau berkumpul. Sedangkan data adalah representasi fakta dunia nyata yang mewakili suatu objek seperti manusia (pegawai, siswa, pembeli, pelanggan), barang, hewan, peristiwa, konsep, keadaan, dan sebagainya, yang diwujudkan dalam bentuk angka, huruf, simbol, teks, gambar, bunyi atau kombinasinya.

\section{HASIL DAN PEMBAHASAN}

\section{Planning (Perencanaan)}

\section{a. Identifikasi Masalah.}

Berdasarkan hasil observasi dan wawancara yang telah dilakukan, maka dapat diidentifikasikan permasalahan yang saat ini dihadapi adalah sebagai berikut:

1) Membutuhkan waktu yang lama untuk melakukan rekapitulasi perhitungan sks mengajar dosen.

2) Masih sering terjadinya kesalahan dalam perhitungan yang menimbulkan keluhan dari dosen.

3) Pimpinan mendapatkan kesulitan dalam pengambilan keputusan.

\section{b. Analisa Kebutuhan.}

Berdasarkan permasalahan tersebut maka dapat didefinisikan kebutuhan fungsional dan non fungsional dari aplikasi perhitungan sks mengajar dosen.

\section{Kebutuhan fungsional.}

1) Sistem menyediakan form untuk memasukkan data master seperti dosen, data jabatan, mata kuliah, kampus dan jadwal mengajar.

2) Sistem mampu menghitung rekap sks mengajar dosen sesuai dengan data yang tersedia.
3) Waktu yang dibutuhkan sistem untuk melakukan penyimpanan data maksimal 2 detik per input.

4) Waktu yang dibutuhkan sistem untuk melakukan proses perhitungan sks mengajar maksimal 3 menit per proses.

\section{Kebutuhan non-fungsional.}

1) Seluruh pengguna aplikasi dapat melakukan pengaksesan data tanpa harus melakukan login berulang kali, pengguna hanya harus melakukan satu kali login untuk sistem operasi.

2) Aplikasi hanya bisa diakses dari dalam jaringan perusahaan.

3) Aplikasi harus tersedia dalam 24 jam perhari, 7 hari perminggu.

4) Jika pada saat proses penarikan data dilakukan terjadi kegagalan yang dikarenakan beberapa hal di pusat data, maka data yang terdapat dipusat data tidak boleh rusak, hilang dan dapat dipulihkan.

\section{Design (Perancangan) \\ a. Pemodelan Sistem. \\ 1) Use Case Diagram.}

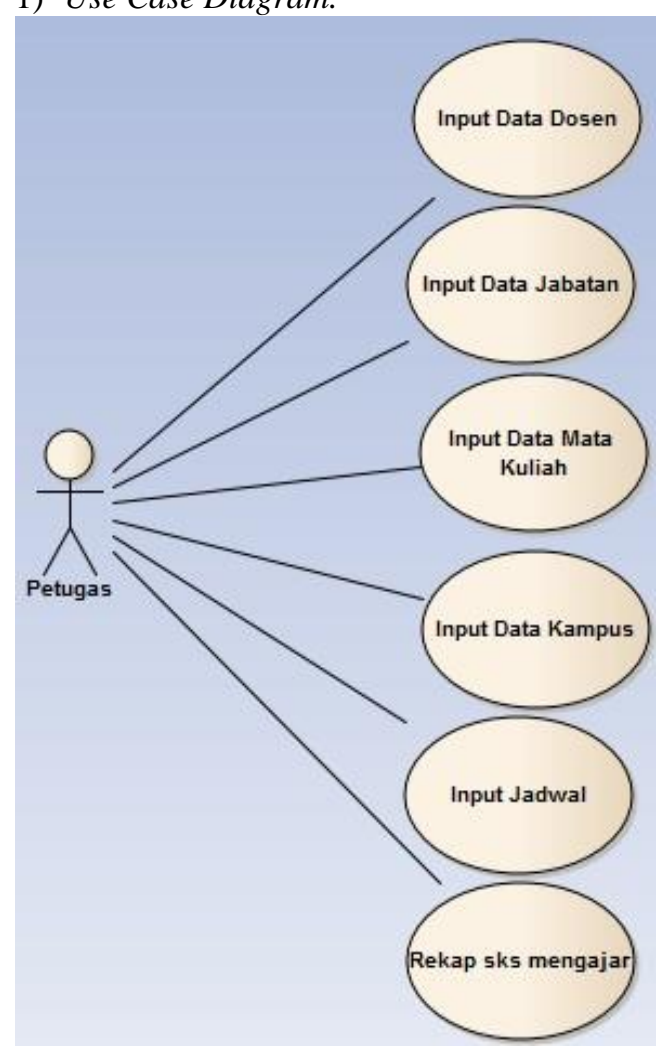

Gambar 3. Use Case Diagram 
2) Activity Diagram

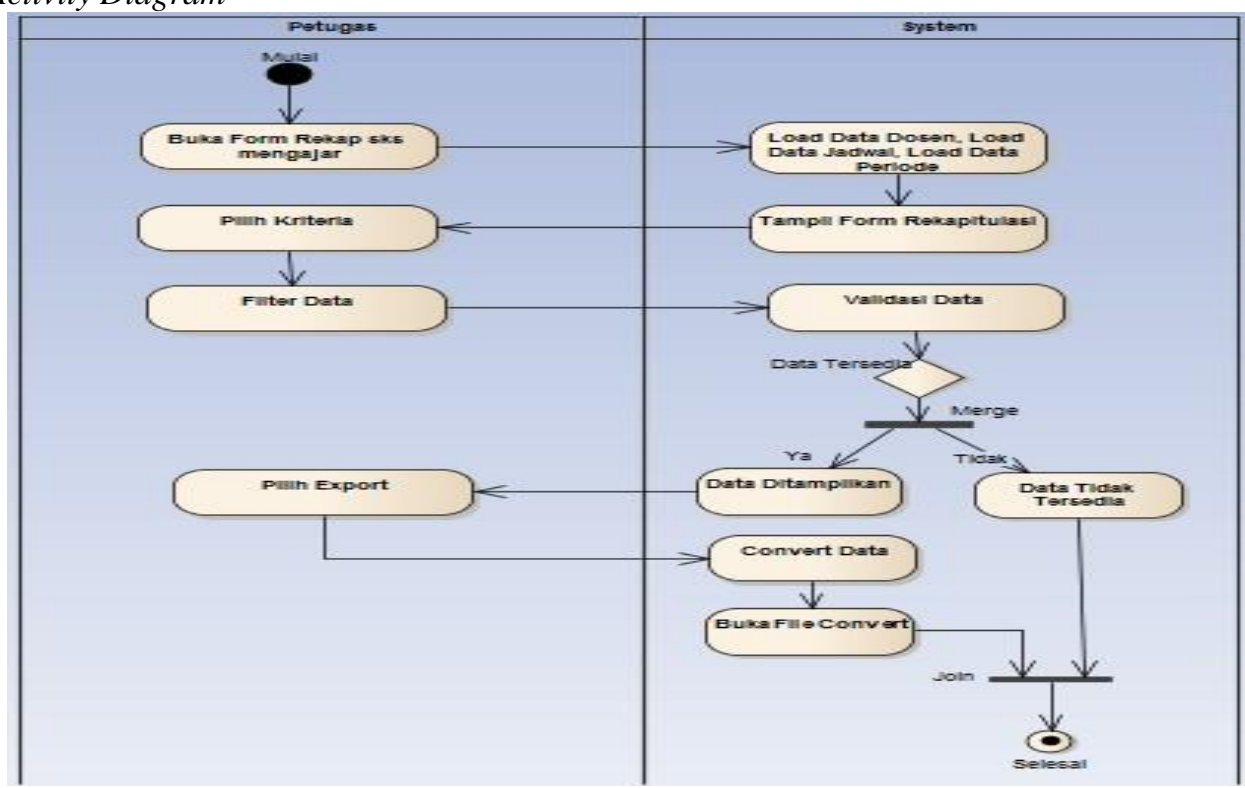

b. Pemodelan Arsitektur.

Gambar 4. Activity Diagram

1) Component Diagram.

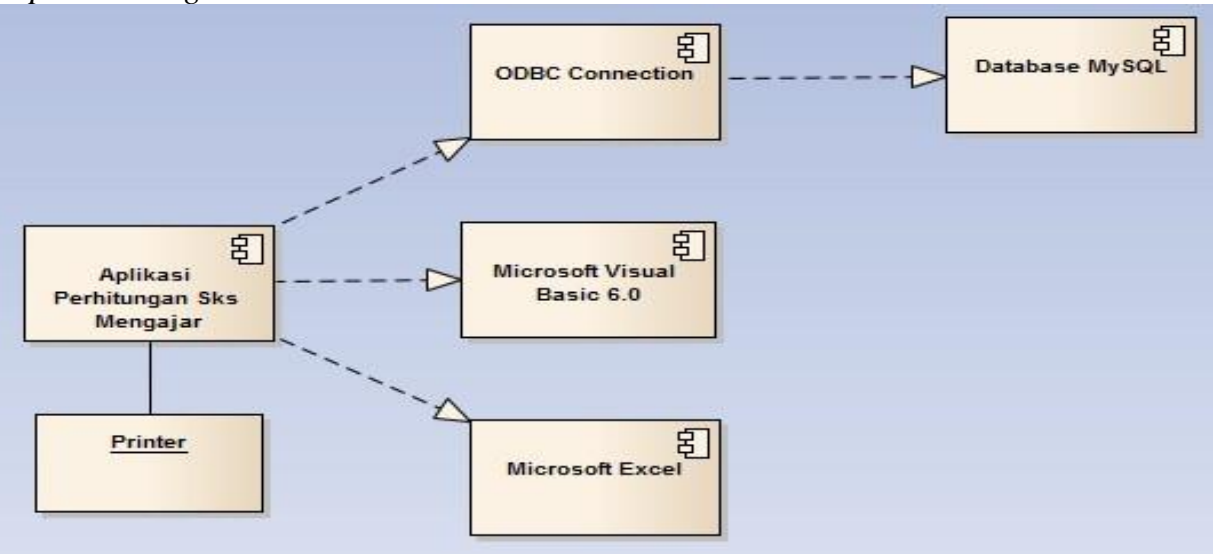

Gambar 5. Component Diagram Aplikasi Perhitungan sks mengajar.

2) Deployment Diagram.

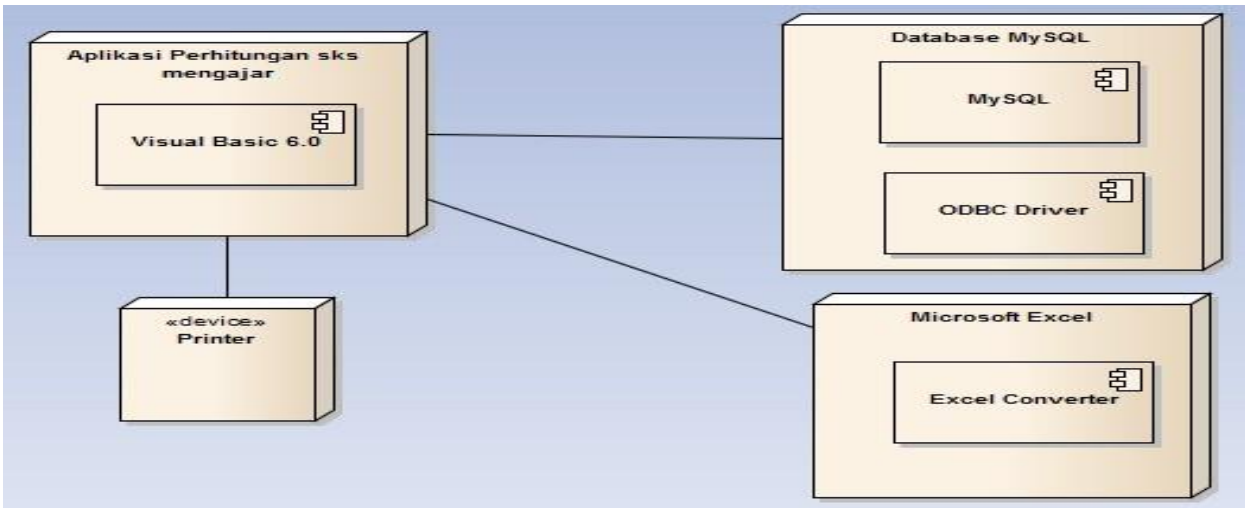

Gambar 6. Deployment Diagram Aplikasi Perhitungan sks mengajar. 
c. Pemodelan Basis Data.

1) Entity Relationship Diagram.

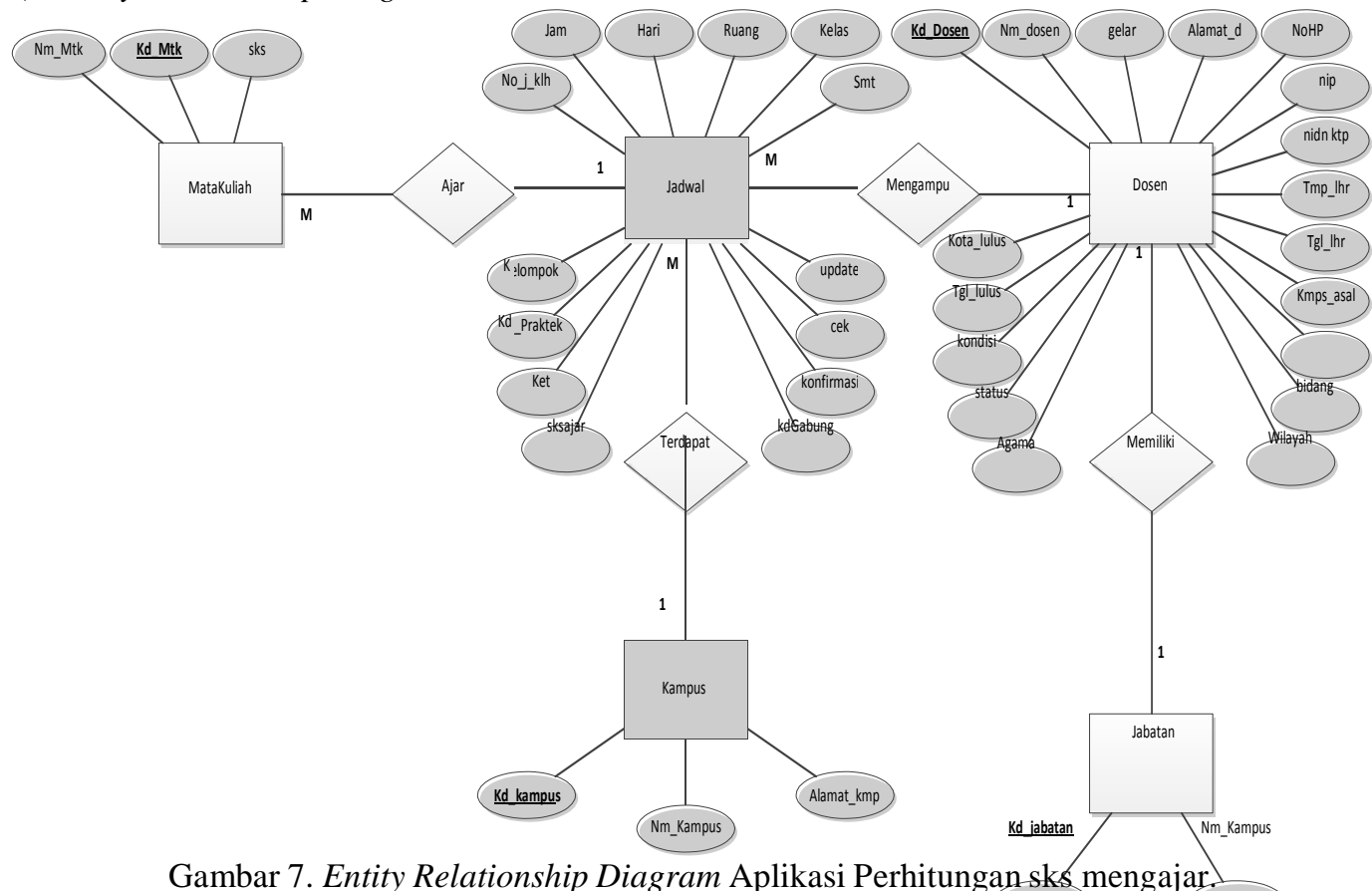

2) Logical Record Structure.

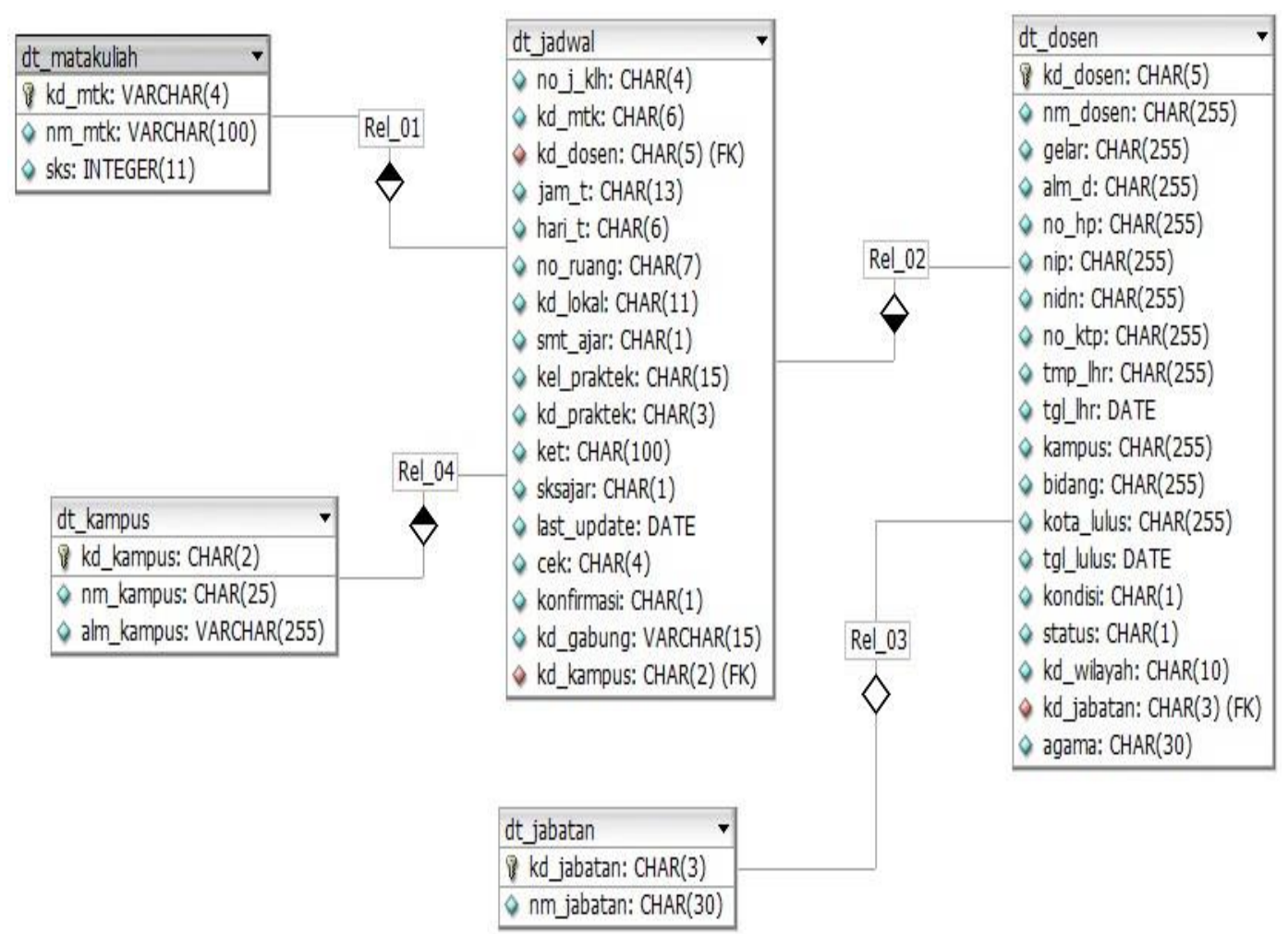

Gambar 8. Logical Record Structure Aplikasi Aplikasi Perhitungan sks mengajar. 
Coding (Pengkodean)

a. Tampilan Rekap sks dosen.

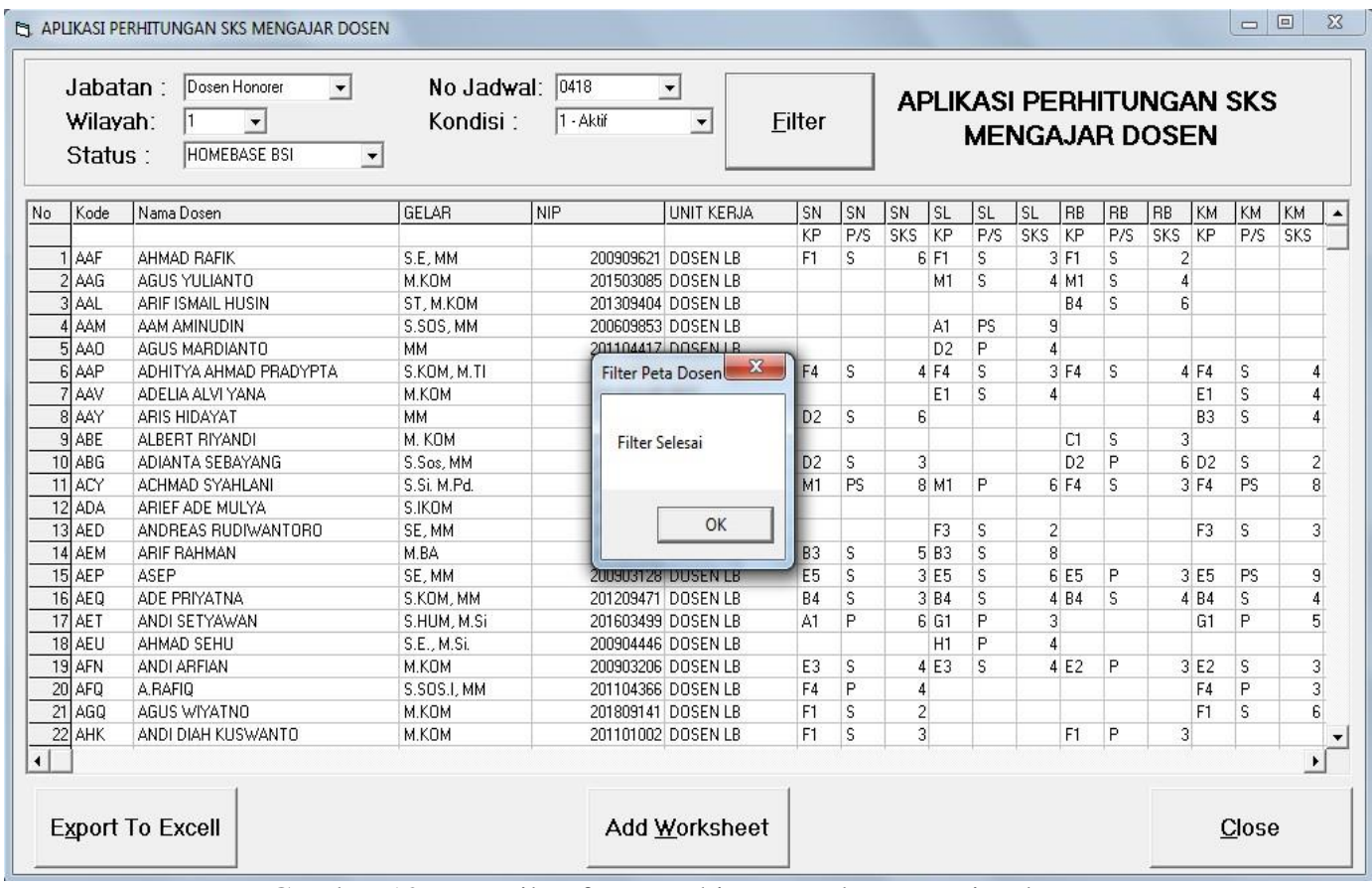

Gambar 12. Tampilan form perhitungan sks mengajar dosen.

\section{e. Tampilan hasil export ke Excel.}

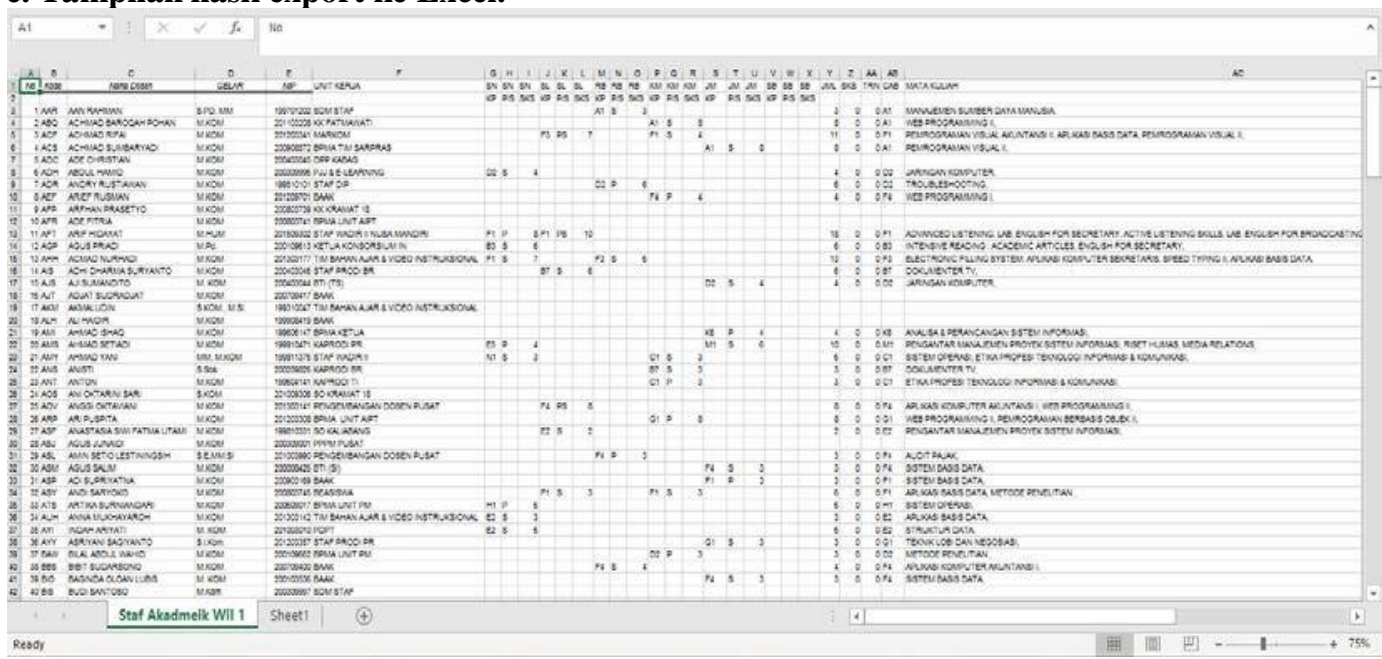

Gambar 12. Tampilan export ke excel.

Testing (Pengujian)

a. Pengujian Sistem.

Pengujian yang dilakukan

menggunakan metode blackbox testing,

berikut adalah skenario pengujiannya:

Tabel 1. Pengujian Aplikasi.

\begin{tabular}{|c|l|c|}
\hline No & \multicolumn{1}{|c|}{ Skenario } & Hasil \\
\hline 1 & $\begin{array}{l}\text { Salah satu atau semua } \\
\text { kriteria tidak diisi } \\
\text { Jabatan }:\langle\text { kosong> }\end{array}$ & $\begin{array}{c}\text { Sesuai dengan } \\
\text { kebutuhan. }\end{array}$ \\
\hline
\end{tabular}

\begin{tabular}{|c|c|c|}
\hline & $\begin{array}{l}\text { Wilayah : <kosong> } \\
\text { Status : <kosong> } \\
\text { No jadwal : <kosong> } \\
\text { Kondisi : <kosong> } \\
\text { Klik Filter maka sistem akan } \\
\text { memberikan notifikasi } \\
\text { bahwa "Data tidak tersedia" }\end{array}$ & \\
\hline 2 & $\begin{array}{l}\text { Semua kriteria diisi dengan } \\
\text { benar } \\
\text { Jabatan : Dosen honorer } \\
\text { Wilayah : } 1 \\
\text { Status : Homebase }\end{array}$ & $\begin{array}{c}\text { Sesuai dengan } \\
\text { kebutuhan }\end{array}$ \\
\hline
\end{tabular}




\begin{tabular}{|l|l|l|}
\hline No jadwal : 1117 & \\
Kondisi : 1-Aktif & $\begin{array}{l}\text { Klik Filter maka sistem akan } \\
\text { menampilkan data yang } \\
\text { diminta. }\end{array}$ & \\
\hline
\end{tabular}

\section{KESIMPULAN}

Kesimpulan yang dapat dijabarkan dari hasil penelitian ini adalah aplikasi perhitungan sks mengajar yang dibangun dengan menggunakan Microsoft Visual Basic 6.0 mampu memberikan kemudahan dalam melakukan proses perhitungan sks mengajar dosen dengan cepat dan akurat. Hasil keluaran aplikasi ini digunakan sebagai dasar proses pengambilan keputusan.

Saran untuk pengembangan aplikasi ini dapat dilakukan secara realtime agar datanya dapat digunakan kapan saja saat dibutuhkan.

\section{DAFTAR PUSTAKA}

Krismiaji. (2015). Sistem Informasi Akuntansi (4th ed.). Yogyakarta: UPP STIM YKPN.

Lubis, B. O. (2016). Penerapan Global Extreme Programming Pada Sistem Informasi Workshop, Seminar Dan Pelatihan Di Lembaga Edukasi. Jurnal Informatika, 3(2), 234-246. Retrieved from http://ejournal.bsi.ac.id/ejurnal/index.p $\mathrm{hp} / \mathrm{ji} /$ article/view/1055

Nugroho, A. (2010). Rekayasa Perangkat Lunak Berbasis Objek dengan Metode USDP. Yogyakarta: Andi Offset.

Pardede, A. M. H., \& Novriyenni. (2015). SISTEM PENDUKUNG KEPUTUSAN PEMBERIAN JUMLAH SKS MENGAJAR DOSEN PADA STMIK KAPUTAMA BINJAI. In Konferensi Nasional Pengembangan Teknologi Informasi dan Komunikasi (KeTIK 2015) (pp. 12-19).

Romney, M. B., \& Steinbart, P. J. (2015). Accounting Informations Systems (13th ed.). England: Pearson Educational Limited.

Stefano. (2014). Cara Mudah Membangun Sistem Informasi menggunakan VB. NET dan Komponen DXPERIENCE (1st ed.). Yogyakarta: Andi Offset.
Sukamto, R. A., \& Shalahuddin, M. (2014). Rekayasa Perangkat Lunak. Bandung: Informatika.

Supriyatna, A. (2018). Metode Extreme Programming Pada Pembangunan Web Aplikasi Seleksi Peserta Pelatihan Kerja. Jurnal Teknik Informatika, 11(1), 1-18. https://doi.org/10.15408/jti.v11i1.6628

Wina Widiati. (2017). Aplikasi Pengolahan Data Koperasi Simpan Pinjam Untuk Meningkatkan Pelayanan Koperasi. IJSE - Indonesian Journal on Software Engineering, 3(2), 44-53. Retrieved from http://ejournal.bsi.ac.id/ejurnal/index.p hp/ijse/article/view/2821 